\title{
Investing American Recovery and Reinvestment Act Funds to Advance Capability, Reliability, and Performance in NASA Wind Tunnels
}

\author{
George H. Sydnor ${ }^{1}$ \\ NASA Aeronautics Test Program, Langley Research Center, Hampton, Virginia, 23681
}

\begin{abstract}
The National Aeronautics and Space Administration's (NASA) Aeronautics Test Program (ATP) is implementing five significant ground-based test facility projects across the nation with funding provided by the American Recovery and Reinvestment Act (ARRA). The projects were selected as the best candidates within the constraints of the ARRA and the strategic plan of ATP. They are a combination of much-needed large scale maintenance, reliability, and system upgrades plus creating new test beds for upcoming research programs. The projects are: 1.) Re-activation of a large compressor to provide a second source for compressed air and vacuum to the Unitary Plan Wind Tunnel at the Ames Research Center (ARC) 2.) Addition of high-altitude ice crystal generation at the Glenn Research Center Propulsion Systems Laboratory Test Cell 3, 3.) New refrigeration system and tunnel heat exchanger for the Icing Research Tunnel at the Glenn Research Center, 4.) Technical viability improvements for the National Transonic Facility at the Langley Research Center, and 5.) Modifications to conduct Environmentally Responsible Aviation and Rotorcraft research at the 14x22 Subsonic Tunnel at Langley Research Center. The selection rationale, problem statement, and technical solution summary for each project is given here. The benefits and challenges of the ARRA funded projects are discussed. Indirectly, this opportunity provides the advantages of developing experience in NASA's workforce in large projects and maintaining corporate knowledge in that very unique capability. It is envisioned that improved facilities will attract a larger user base and capabilities that are needed for current and future research efforts will offer revenue growth and future operations stability. Several of the chosen projects will maximize wind tunnel reliability and maintainability by using newer, proven technologies in place of older and obsolete equipment and processes. The projects will meet NASA's goal of integrating more efficient, environmentally safer, and less energy consuming hardware and processes into existing tunnel systems. These include Environmental Protection Agency-approved refrigerants, energy efficient motors, and faster, flexible tunnel data systems.
\end{abstract}

\section{Nomenclature}

$\begin{array}{ll}g / m 3 & =\text { grams per cubic meter } \\ h p & =\text { horsepower } \\ \text { kcmil } & =\text { thousand circular mils } \\ \text { psia } & =\text { pounds per square inch, absolute } \\ \text { psig } & =\text { pounds per square inch, gauge } \\ r p m & =\text { revolutions per minute } \\ \text { scfm } & =\text { standard cubic feet per minute } \\ \text { ATP } & =\text { Aeronautics Test Program } \\ D C S & =\text { distributed control system } \\ D R S & =\text { Data Reduction Software } \\ \text { DDS } & =\text { Dynamic Data System } \\ E P A & =\text { Environmental Protection Agency }\end{array}$

${ }^{1}$ Capital Investment Projects Manager, Aeronautics Test Program, MS188C, NASA Langley Research Center, Hampton, VA. 
NASA $=$ National Aeronautics and Space Administration

$N T F \quad=$ National Transonic Facility

\section{Introduction}

NASA's Aeronautics Test Program (ATP) was created to preserve and promote flight and ground testing capabilities of a select set of research facilities in the United States. Four NASA centers - Ames Research Center in Mountain View, CA; Dryden Flight Research Center in Edwards, CA; Glenn Research Center in Cleveland, OH; and Langley Research Center in Hampton, VA - operate these facilities providing an extensive array of services in their respective areas of expertise. Responsible for asset management of these facilities within the Aeronautics Research Mission Directorate (ARMD), ATP directs investments in facilities and capabilities that grow and sustain the needed tools for the aeronautics research and testing community. As with most large, complex assets, these are constantly in need of major and minor repairs, technology advancements, and modifications to support the current and upcoming needs of various NASA programs, DOD, and industry customers. Strategic selection of investment projects with a constrained budget usually means that only the highest priority requirements are met. However, because of the ARRA initiative, ATP has the singular opportunity to vertically advance the overall health of its portfolio and provide urgently needed test capabilities. Using these funds, ATP is investing in five significant projects across NASA's ground-based test facilities.

In February 2009, the American Recovery and Reinvestment Act was signed into law. Paramount to success in executing this law are preserving and creating jobs, spurring technological advances in science and health, and promoting economic recovery. NASA supports and achieves these national goals through the funding selections made in its program and infrastructure. From the ARRA, NASA received a total of \$1B of funds spread across its four Mission Directorates. The ARMD received $\$ 150 \mathrm{M}$, of which ATP was allocated $\$ 46.6 \mathrm{M}$ for facility and capability upgrades.

ATP chose projects that ranked highest when matrixed between the ARRA funding requirements and the ATP strategic plan for capability advancement and maintenance recapitalization. Each of these ground-based facilities is in high demand and need significant investments. These projects represent a good balance of maintenance, upgrades, and new ground-test capabilities that would be impossible to achieve simultaneously without significant funding as provided by the ARRA. By proposing the projects described below for execution ATP successfully demonstrated direct project correlation to the ARRA funding criteria, thereby securing over 38\% of NASA's total ARRA infrastructure investment dollars. The rationale, in part, was based on workforce demographics required to execute these projects. Contracted firms are a balance of large and small businesses, including both blue and white-collar workers. Skill sets required are varied - construction workers, engineers, designers, manufacturers, and fabricators across the nation are employed. The project activities stimulate economic growth through directly contracted labor pools and through goods and services provided across the country for supplies that are both non-specialized and aerospace related. The accomplishment of these projects will enable continued and expanded wind tunnel test capabilities providing national economic benefits by enabling new research jobs, sustaining existing workforce, and increasing tunnel availability by minimized downtime.

\section{Compressor Reactivation at the Ames Unitary Plan Wind Tunnel}

The Unitary Plan Wind Tunnel (UPWT) located at the Ames Research Center (ARC) has been instrumental in the development of virtually every domestically produced commercial transport and military fixed-wing airframe since the 1960s. The wind tunnel complex consists of two operating variable Mach number, variable Reynolds number wind tunnels, and their associated auxiliary subsystems. The two tunnels have complimentary Mach envelopes covering the transonic range (0.25-1.45) in the 11-Foot and supersonic range (1. 5 to 2.50) in the 9x7. In both closed-loop tunnels, circuit pressure is varied to achieve Reynolds numbers conducive to scaling for test section and model sizes. The circuit pressure is adjusted with a high capacity Make Up Air (MUA) compressor system and a network of piping, valves, and storage spheres to deliver or remove the air from the tunnels. The singular MUA compressor was put into service in 1956. It consists of a dual-stage, Clark Brothers centrifugal compressor rated at 50,000 scfm driven by a General Electric 15,000 Hp induction motor through a Farrel Brothers speed-increasing gearbox (318/4200 rpm). This MUA compressor system is well beyond its design life and represents a critical single point failure for UPWT operation. The MUA system, over 55 years old, remains largely as it was originally built in 1954. The used drive motor, on the other hand, was scavenged from the early ARC 16-Foot Subsonic Wind Tunnel when it was converted in 1953 to the 14-Foot Transonic Tunnel. The motor originally went into service in December 1941, and at 69 years old, the motor has been well maintained, but never rewound. 
Already at an austere age, this equipment continues to run every day, and component failures cause unplanned downtimes at an ever-increasing rate. The probability of unscheduled downtime and catastrophic failure due to problems with 50-70 year old machinery is high. Due to the single-point failure risk the MUA system represents, a significant amount of effort and money is dedicated to keeping this vital equipment operational. As one might expect, spare parts for this equipment long ago became unavailable and must now be individually manufactured. Lead times of 6 to12 months and costs upwards of $\$ 1$ million for major components can be expected in the event of a failure. An unplanned shutdown with that much test program schedule impact would be devastating to a customer.

The Mitsubishi Heavy Industries (MHI) MUA compressor system at Building N206 was installed as part of the 12-Foot Pressure Wind Tunnel Restoration Project in 1994. It was provided to pressurize the closed circuit tunnel. The MUA consists of a 12,000 Hp, $1200 \mathrm{rpm}$, synchronous motor driving a fourstage, integral gear, centrifugal compressor delivering $50,000 \mathrm{scfm}$. Since its initial activation, the MHI compressor has less than 2000 hours of operation and remains in excellent overall condition.

A process air tie line was originally installed at ARC in the 1970s and was replaced for the most part in the 1990s. The tie line was intended to allow sharing of air services and mitigate single point failures at several facilities, including the 12-Foot

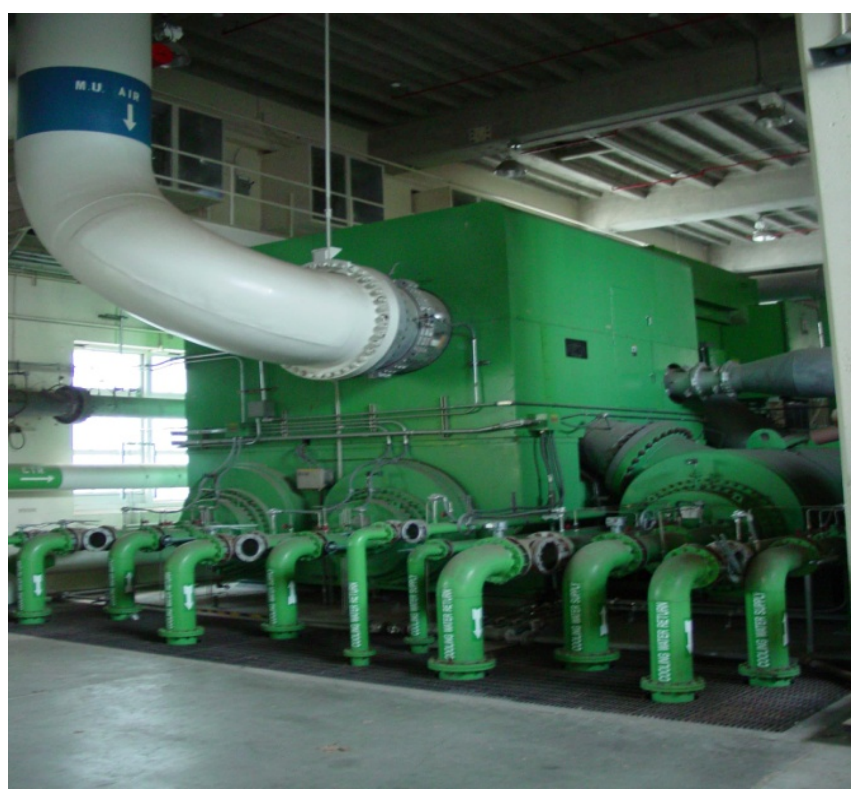

Figure 1. MHI Make up air compressor, out of service.

Pressure Tunnel and the UPWT. In 2006, an electrical failure damaged the feeder cables for the 12-Foot Tunnel Complex switchgear, forcing a deactivation of the entire facility, including the MHI compressor and subsystems. It has sat idle and unpreserved since that time. Because the other facilities were no longer operating at ARC, the tie line was isolated and unmaintained.

The Compressor Reactivation Project will provide the UPWT with higher reliability and more efficient operations. Primarily, the MHI compressor, via the tie line, will become the primary air supplier for the UPWT, increasing the facility's reliability, reducing unplanned facility downtime, and reducing the risk of a major facility outage. Second, when practical, operating the MHI and Clark MUA systems together improve facility productivity by reducing pressurization or evacuation times. Thirdly, the addition of new piping and valves to the 11-Foot tunnel circuit provides capabilities and operating flexibility that will allow additional productivity gains. Finally, there are significant safety advantages of reactivating the MHI compressor, particularly for the 9x7 tunnel where shock wave energy across the model during an unstart can be reduced. The reactivation project consists of the following major work packages.

\section{A. Compressor Refurbishment}

Because the MHI compressor, shown in Fig. 1, has not run nor been maintained for almost five years, several areas of work are underway to bring the machine to operational condition. During the process, any damage found is being repaired. The reactivation approach includes general refurbishment activities with large mechanical rework being deferred until it has been determined that the work is actually required or not. All work is being executed at the compressor site.

- Clean and inspect the unit on site to determine current condition

- Open; inspect/repair heat exchanger tubes in the intercoolers and aftercooler, reassemble, and hydro test

- Integral gearbox pinion and bull gear cleaning and inspection

- Lubrication system overhaul, flush and refill

- Replace miscellaneous parts such as gaskets and seals

- Visually inspect piping compressor connections for defects

- Visually inspect the foundation for cracks

- Refurbish the Air Inlet House, adding safe access, rainproof roof, condensation heaters, and install new filters

- Perform motor maintenance, re-energize motor space heaters 


\section{B. Air Dryer Upgrades}

The existing downstream air dryer for the MHI compressor is known to have operating deficiencies support of the UPWT, including poor duty cycle and inadequate drying capability. During the original start-up and commissioning of the dryer, the regeneration blower fan blades came loose due to incorrect mechanical integration and damaged the system. The air dryer was reconfigured and additional devices were added to improve system operation and safety. However, the performance necessary to support the UPWT independently was never achieved. In order to improve the efficiency of the activated alumina adsorbent material, higher tower pressure is required. The existing backpressure butterfly control valve uses a hydraulic actuator that is unable to hold higher pressure with the existing controller configuration. This deficiency is being corrected by adding fine and coarse valves and integrated controls to improve the efficiency.

The dryer is also being upgraded with high-performance adsorber bed material, a larger capacity electric regeneration heater, and fan capacity to meet the duty cycle requirements. Because of its obsolete and marginal controls, the dryer is being outfitted with a completely new control system that matches the UPWT distributed control system platform. The new hardware and software will assure proper control and interlocking of the dryer valving for safety concerns associated with a dual bed regenerative dryer system. The air dryer is now sized to dry $50,000 \mathrm{scfm}$ of 155 psia saturated air at $95^{\circ} \mathrm{F}$ to outlet moisture content of less than 0.4 grains of $\mathrm{H}_{2} \mathrm{O}$ per pound of dry air.

\section{Tie Line Inspection and Repair}

The predominantly thirty four inch, 1500' tie line is underground from the 12 Foot Tunnel for 1200 ' and then rises above ground for the remainder of the run. The pressure drop and evacuation times of the tie line between the MHI compressor inlet and the isolation valve at UPWT has been checked by calculation to verify the value of both pressurization and evacuation modes of the remotely located compressor. The underground section of pipe has been partially inspected and subsequently analyzed as part of the project. Robotic visual inspection was performed on the first 550' of the pipe interior starting from the UPWT entry point to provide data for condition assessment. The pipeline's external coating has been spot-checked by the impressed direct current method. The conductivity of the piping relative to the soil was also tested.

The pipe is in generally good condition. The internal video inspection showed corrosion associated with the pipe joint welding at several locations. Significant corrosion was also noted inside the steel pipe surface near the drainpipe connections because of standing condensation collection. No significant external corrosion or pipeline coating damage was indicated from the impressed current testing. The soil resistivity survey indicated that the soil along the pipeline is moderately corrosive, and would contribute to pipe deterioration. A cathodic protection system has been recommended to minimize external corrosion from soil-pipeline interaction, and will be added to the facility maintenance list. Repairs to the five low point drains and affected pipes will be accomplished and then a full up pressure test performed prior to putting the tie line back in service.

\section{Anti-Surge Compressor Control System}

The existing anti-surge control system for the MHI compressor is integrated into the obsolete control platform originally provided with the compressor. A separate, dedicated anti-surge controller will be installed to perform high-speed opening of the compressor's surge relief valve. The anti-surge control system hardware includes a set of main and back-up controllers, a redundant control selector, and power supply components. Not only does this solution provide redundant safety systems it assures complete independence between the compressor controls and the anti-surge control.

\section{E. Feeder Cables}

The existing medium voltage conductors supplying power to the compressor are beyond their recommended life and four of the nine of the conductors have failed. This leaves five out of nine existing conductors operable, an insufficient quantity to power the MHI MUA compressor. It was considered, but not recommended, to replace just the failed cables, but because of the intertwined installation and damaged cable supports, it was decided to replace all cables so that the compressor feeder has consistent electrical characteristics. The existing 2000' long conductors are being replaced with $1250 \mathrm{kcmil}$ ethylene propylene rubber insulated conductors rated for $105^{\circ} \mathrm{C}$ continuous full load capacity. The new conductors will follow the same route as the existing conductors. Prior to installation work, all existing and other abandoned cables will be removed to ease the installation of the new cable runs. As the new conductors are pulled in, deteriorated conductor supports will be replaced. 
Because the cable replacement effort will leave one building (Building N237) without power while the replacement of the conductors is being performed, a temporary feeder and portable generator has to be installed for the duration of the cable replacement work package execution.

\section{F. Controls and Instrumentation}

The existing control of the MHI compressor is integrated into the mothballed 12 Foot Pressure Tunnel control system. To remotely operate the compressor from the UPWT, which has a different control platform, a new controls integration scheme is required. The reactivation controls work consists of a new fiber optic link between the two facilities and controls upgrade to the Emerson Ovation ${ }^{\mathrm{TM}}$ DCS.

The current Bently-Nevada ${ }^{\mathrm{TM}} 3300$ health monitoring system for the MHI compressor is a multi-instrument system that monitors the temperature of drive motor windings, lubrication oil, cooling water, and air as well as vibration of the compressor and motor shafts. The newer 3500 series system has current support and more features, and consequently is replacing the existing system. The upgraded health monitoring will be interfaced directly to the UPWT DCS allowing direct collection of data. In order to maintain integration of the temperature signals with the facility data system, the new 3300series system is configured to also transmit temperature data via the data network. This provides UPWT a fully integrated health monitoring system; recording data continuously for predictive maintenance decisions. This integration method of sensor/control and subsystem/data recording allows UPWT to use equipment condition assessments to determine the most effective time to schedule and perform maintenance.

\section{Ice Crystal Capability at the Glenn Propulsion Systems Laboratory}

The Propulsion Systems Laboratory (PSL) is one of the nation's premier direct connect altitude simulation facilities for full-scale gas turbine engine and propulsion system research. It is NASA's only ground-based test facility that can provide true flight simulation for experimental research on air-breathing propulsion. The laboratory can simulate altitudes to 90,000 feet and speeds up to Mach 6. The PSL is equipped to conduct full-scale component testing for basic research, advanced aircraft, space transportation, general-aviation and hypersonic propulsion.

Since 1988, the Engine Harmonization Working Group (EHWG) has documented over 140 engine power-loss events (surge, stall, rollback, or flameout) attributed to mixed phase (water and ice) and ice crystal atmospheric environments. Ice accumulation on engine components can result in blockage to airflow, thereby starving the engine combustor leading to engine loss of power. In addition, ice buildup can shed and cause engine stalling or result in physical damage to engine components. Aircraft engines must be certified to operate in icing conditions without serious loss of power, loss of thrust, or damage to the engine hardware because of ice shedding. Demonstrating compliance with this requirement is usually carried out in ground test facilities without altitude simulation capability. The fundamental physics of ice buildup and shedding is poorly understood, and research at altitude conditions is required to validate information derived from ground testing.

To this point, NASA has worked with industry and other government agencies to develop and define the needed facility requirements for reproducing engine icing conditions in flight. Implementation of this new capability will provide engine manufacturers a test bed for understanding and mitigation of engine ice accretion. Armed with this knowledge, safer engines can be designed and manufactured, eventually passing the Federal Aviation Administration's proposed FAR 33 Appendix D engine icing certification tests.

The modifications at PSL's Test Cell 3 will mass producing ice crystals in a controlled environment and direct them into an operating engine. The ice generation system consists of unique crystal-producing spray bars, support systems hardware, and fluid processes. A tunnel transition section will be fabricated and installed to guide the ice crystals into an operating engine. Table 1 lists the requirements for conducting icing research at the PSL Test Cell 3.

The PSL icing method will produce small ice particles using water with air-assisted atomization techniques. In this process, atomized water droplets are cooled to insure that all ice particles produced have fully frozen prior to approaching the inlet of the engine being tested. This icing system will be capable of producing glaciated icing clouds with a density up to $9.0 \mathrm{~g} / \mathrm{m}^{3}$. The process uses chilled water and air as cold as $35^{\circ} \mathrm{F}$ at the atomizing nozzles. Colder temperatures are not necessary or recommended in order to avoid possible freezing within the supply lines. As small water particles are produced, their temperature drops almost immediately to $32^{\circ} \mathrm{F}$, the freezing temperature of water. The particles stay at that temperature until all latent heat of fusion has been removed, at which point it becomes $100 \%$ frozen. Any additional cooling reduces the ice particle temperature closer to its surrounding air. 


\begin{tabular}{|c|c|c|}
\hline \multicolumn{3}{|c|}{ Specified Requirement } \\
\hline Specification & Minimum & Maximum \\
\hline Altitude (pressure) & $4000 \mathrm{ft}$ & $40,000 \mathrm{ft}$ \\
\hline Inlet Total Temperature & $-60^{\circ} \mathrm{F}$ & $15^{\circ} \mathrm{F}$ \\
\hline Mach Number & 0.15 & 0.80 \\
\hline Air Flow Rate & $10 \mathrm{lbm} / \mathrm{sec}$ & $330 \mathrm{lbm} / \mathrm{sec}$ \\
\hline IWC (ice water content) & $0.5 \mathrm{~g} / \mathrm{m}^{3}$ & $9.0 \mathrm{~g} / \mathrm{m}^{3}$ \\
\hline MVD (mean volumetric diameter) & $40 \mu$ & $60 \mu$ \\
\hline Run Time & Continuous up to 45 minutes \\
\hline
\end{tabular}

\section{A. Ice Crystal Process Subsystems}

The design, fabrication, and installation of the subsystems necessary to generate ice crystals was prioritized to allow early execution; thus supporting the obligation metric of the ARRA. These systems are currently being constructed and installed at the facility. To produce the ice crystals, three processes are required: Icing Water, Atomizing Air, and Area Cooling Air.

The Icing Water System consists of potable water passed through a liquid-to-liquid heat exchanger, cooling the water to $35^{\circ} \mathrm{F}$ using a $15 \%$ glycol solution. The water is filtered through a $25 \mu$ duplex cartridge filter to initially remove foreign particles. Downstream of the heat exchanger, via an inductor, particles are injected into the water to aid the ice-starting, or nucleation process. The water is seeded with additives similar to those used to make snow at ski resorts. The water/particle mixture is contained in a storage tank that acts as a flow buffer once the operation of the system begins. A separate agitation loop keeps the particles in suspension as well as passing through the heat exchanger to maintain temperature. The water flow rate can be varied from 0.0 to 12.7 gallons per minute, with a supply pressure of 350-400 psig. Pressure control is provided by using a backpressure control valve at the spray bar nozzle banks with a pump and recirculation loop.

The Atomizing Air will be supplied from the facility's compressed air header with a nominal dewpoint of less than $25^{\circ} \mathrm{F}$. This portion of the 100 psig air will be chilled to $35^{\circ} \mathrm{F}$ using an air to liquid glycol heat exchanger. Depending on the number and size of ice spray nozzles activated for a given engine test, the Atomizing Air system can supply up to $2500 \mathrm{scfm}$.

The Area Cooling Air will also be supplied from the facility header. Since this air must absorb additional heat from the Test Cell 3 inlet air stream laden with water and atomizing air, it has to be further cooled, and therefore must be extremely dry. Additional drying is provided through a desiccant-type dryer down to $-40^{\circ} \mathrm{F}$ dewpoint. The air is pre-cooled using the same method as the Atomizing Air, and then further cooled to $-40^{\circ} \mathrm{F}$ via a liquid nitrogen heat exchanger. To obtain this level of cooling, a 3000 gallon liquid nitrogen dewar supply at 30 psig and $-300^{\circ} \mathrm{F}$ will be installed. Depending on the nozzle and test configuration, this system can deliver up to $2500 \mathrm{scfm}$ of supercooled air.

\section{B. Spray Bars and Nozzles}

The more complex spray bar and less-understood nozzle designs continued past the subsystem design work, and included a prototype test of the design to demonstrate icing performance and validate the computational fluid dynamics (CFD simulation models. Ten individual spray bars with a total of 224 individual spray nozzles will be mounted on three vertical struts in the Test Cell 3 plenum. The spray bars consist of epoxy-fiber composite spar and skin structure over an internal metal structure. The spray bars have the control flexibility to isolate flow to each individual nozzle, allowing many different spray patterns and ice

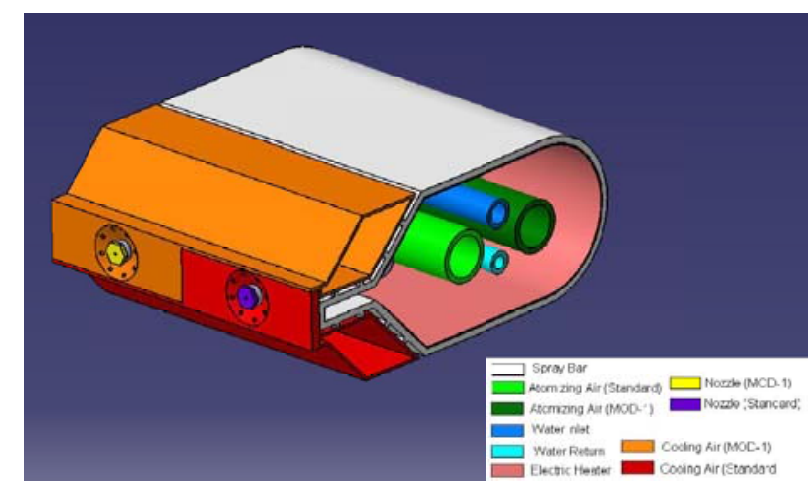


crystal densities. The machined spray bar contains integrated tubes, valving, and manifolds allowing for a uniform icing envelope across the total flow area. The mounting arrangement requires plenum modifications to insert and support the bars, as well as providing manifolds for the Icing Water, Atomizing Air, and Cooling Air. Each spray bar also has electrical heaters to maintain temperature within the bar as well as insulation to protect it from the plenum flow conditions. At the inboard end of each spray bar, the water inlet turns $180^{\circ}$ and exits the plenum, returning to the closed loop icing water system. Figure 2 shows an exploded cut-away view of the spraybar.

\section{Test Cell 3 Transition Section}

A removable, epoxy-fiber composite transition section has been designed and will be fabricated and installed to provide a smooth transition from the larger Test Cell 3 plenum diameter to the smaller engine inlet diameter (approximately 18' to 7.5'). The transition section outer mold line affects how the ice crystal distribution (quantity and size) profile appears to the engine inlet. For ease of fabrication and installation, this transition section consists of multiple epoxy fiber panels that interlock to provide a contiguous transition section. It is envisioned that custom fitting of the section will be necessary to accommodate the existing features of the plenum wall, such as the crane rail. Figure 3 is the output of a CFD simulation showing Mach number distribution with the curvilinear transition section modeled between the test cell plenum and the engine inlet.

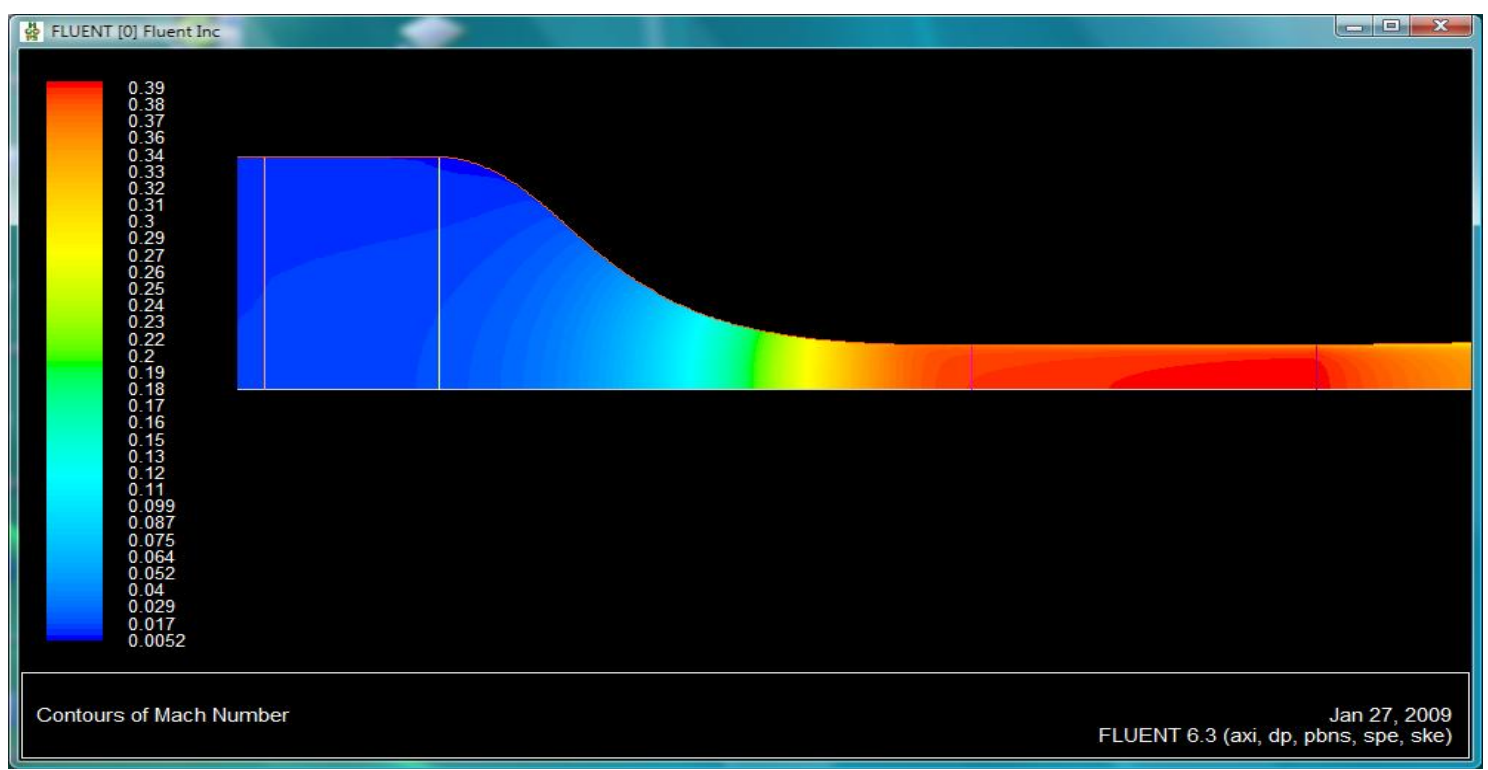

Figure 3. Simulated Mach number distribution using a curvilinear transition section.

\section{New Refrigeration System and Tunnel Heat Exchanger for the Glenn Icing Research Tunnel}

As the nation's largest refrigerated wind tunnel, the Icing Research Tunnel (IRT) simulates and tests the effects of in-flight icing on various aircraft components and scale models. Built at the end of World War II, the IRT was instrumental in developing and testing ice-protection systems for early piston- and propeller-driven aircraft. The IRT continues to be very instrumental in the on-going development and certification of ice protection systems and in understanding icing phenomena.

The IRT is in high demand by NASA, DoD, and industry; running test programs 150-200 days per year. The new refrigeration system will replace the original refrigeration system installed in 1943. Through repairs and modifications, the existing system has lost low-temperature cooling capability over time. A planar-style tunnel heat exchanger (HEX) replaced the vintage W-style HEX in 1999. This modification was coupled with substantial tunnel circuit modifications that improved the flow quality problems associated with the air passage through the original HEX. Once the tunnel was placed back in service, it was discovered that ice formation and shedding on the exit edge of the planar HEX was causing ice erosion on subject models, reducing test quality. This project will provide a completely new and modern refrigeration system and a new state of the art heat exchanger mounted in the tunnel. The new Integrated Refrigeration System coupled with the new cascade heat exchanger will provide several important customer benefits. For testing capability, the new equipment will greatly reduce the current ice erosion region during high speed, low temperature test conditions by reducing air velocity through the new HEX. The 
system will also restore the tunnel's capability to operate to the original minimum capability of $-40^{\circ} \mathrm{C}$ by using a

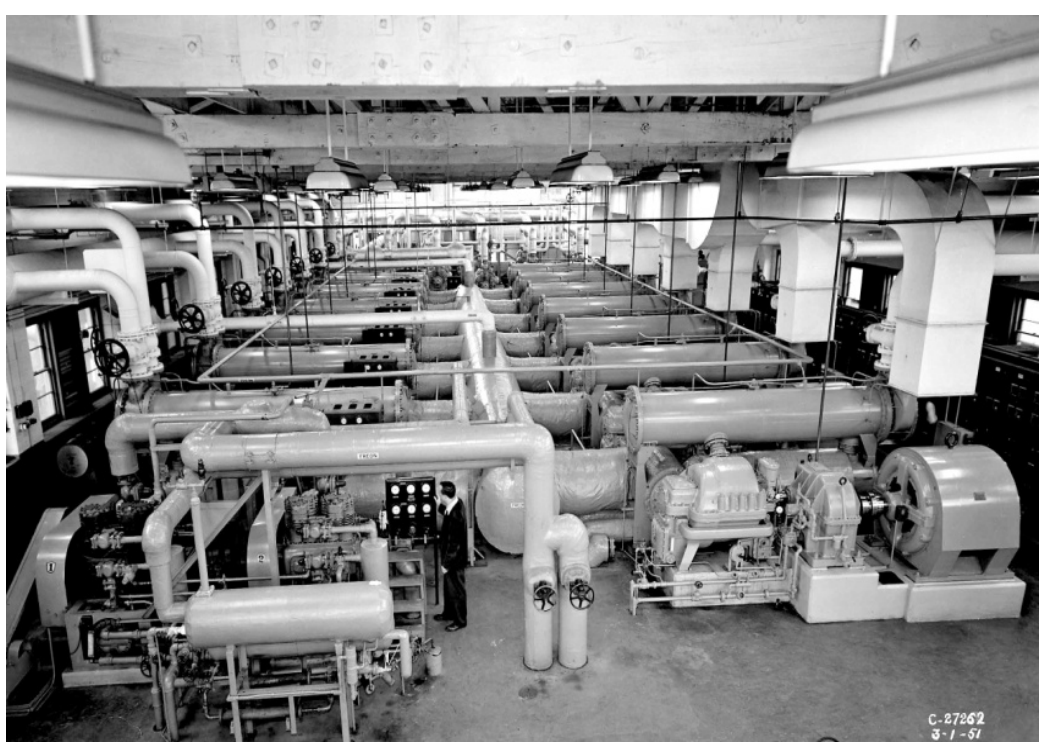

Figure 4. Original IRT Refrigeration System, circa 1951. dual fluid system. Temperature control is enhanced by using a secondary fluid bypass loop to increase the response time to temperature variations. The public continues to benefit from the IRT through its contribution to the development of aircraft that can safely fly through hazardous weather conditions.

A. Integrated Refrigeration System The original IRT refrigeration system used fourteen $1500 \mathrm{Hp}$ centrifugal compressors, and was designed to service the IRT and the Altitude Wind Tunnel (Ref. Fig. 4). The refrigerant was originally R12, but later changed to R134a after the Montreal Protocol was adopted by the United States in 1987. Since its initial installation, the system has undergone many process/equipment changes, all seeming to slowly nibble away at the integrated performance of the refrigeration system coupled to the IRT HEX. Currently leaks in the system are requiring about 10,000 lbs. of refrigerant replacement every two years. The system also suffers from many of the same age-related reliability issues discussed for the UPWT Clark compressor.

The design of a completely new Integrated Refrigeration System consisting of two main segments is underway: A Primary Refrigeration System and a Secondary Coolant System. By integrating the two fluid loops, the primary loop refrigerant compressor stability requirement and setpoint control is greatly relaxed. Additionally, the use of refrigerant as the HEX heat transfer fluid can lead to uncontrolled phase change, thereby disrupting uniform heat transfer across the HEX and resulting in much higher system inefficiency. A pre-engineered metal building is provided to house the equipment and controls. The 70' x 120' building allows for weather protection with minimal enviromental conditioning.

The Primary Refrigeration System will use multiple screw compressors, evaporators, and condensers to provide about 1500 tons of cooling. The primary refrigerant fluid will be R-507. At the $-65^{\circ} \mathrm{F}$ evaporator temperature, this refrigerant operates at a higher pressure than R-134a, and allows more efficient compressor operation. For other factors, such as flammability, toxicity, Global Warming Potential, and Ozone Depletion Potential the two refrigerants exhibit similar characeristics. With the new refrigeration system, the amount of refrigerant is reduced from approximately $24,000 \mathrm{lbs}$ to less than 7,000 lbs and the yearly leakage rate is nearly eliminated.

The Secondary Cooling Loop consists of a piping pass through the Primary Refrigeration System evaporator, a pump skid, reservoir, controls, and distribution piping/valves to the tunnel and the HEX itself. By using a secondary transfer fluid, the control of exit air temperature and temperature uniformity are greatly improved. The secondary loop fluid, Dynalene ${ }^{\mathrm{TM}} \mathrm{HC}-50$, was chosen based on thermal capacity, flammability, toxicity, and other variables. Also, because of its high density and heat transfer coefficient at the desired temperature range, the volumentric flow rate is lower than other candidates. Two $250 \mathrm{Hp}$ supply pumps will deliver a flow rate of over $7000 \mathrm{gpm}$ to the tunnel HEX.

New, modern control of the Integrated Refrigeration System will be implemented to improve operational efficiency and achieve near autonomous operation. This reduces the manpower required to operate the IRT and results in an improved efficiency that will benefit the test customers with more testing hours per test program. Modern leak detection and and life safety systems will be provided for the building. Operation of each gable end roll-up door, and the building ventilation systems are interlocked with the refrigerant leak detectors for safety.

\section{B. Heat Exchanger Fluid Temperature Control Loop}

To very accurately control air temperature exiting the tunnel HEX, additional steps beyond typical variable compressor loading and hot-gas bypass injection methods must implemented. The Integrated Refrigeration System's Secondary Cooling Loop includes a set of opposing flow controls that regulate HEX inlet temperature while 
maintaining constant flow rate of the secondary coolant fluid. The response times of these valves are significantly higher than the refrigerant compressors, vastly improving the controllability and time-to-change setpoint of the HEX. In addition, the stability margin of the temperature control loop increases, reducing component performance specifications. Fluid returning from the HEX is recirculated with the colder supply stream as needed for active bidirectional temperature control. The large secondary coolant reservoir provides a pre-conditioned coolant supply for fast cool-down response at the HEX in response to tunnel commands for changes in test conditions. This decouples the compressor controls, which now only need to maintain primary loop temperature setpoint well below that required of the HEX. Another advantage to this configuration is that the refrigeration system can be started and cooled prior to, and separate from tunnel operations.

\section{Tunnel Heat Exchanger}

The existing tunnel HEX was intended to improve air flow quality and to take advantage of the tunnel circuit leg C-D modifications. The new heat exchanger drastically changed the air and refrigerant flow characteristics, and introduced an unfortunate phenomenon of model ice erosion in the IRT. Figure 5 is empirical data showing where the erosion occurs relative to air speed and temperature. This problem stems from high velocity air passing over the trailing edge of the HEX and forming ice accretion. The ice eventually breaks loose and travels downstream, impinging on the model, eroding the model ice formation under study.

The new tunnel HEX takes advantage of modern design methods and simulations calibrated with abundance of experience from IRT and data from other existing climate research tunnels. The requirements for the new HEX combine the best features of the original W-style HEX and the current improved flow qualities of the current planar HEX. Performance requirements for pressure drop, tunnel blockage, air stream velocity, heat transfer, temperature uniformity, and flow quality are elements of the new HEX design criteria. The current approach to the new heat exchanger indicates performance that meets all of the specifications criteria, with only one or two minor exceptions. In some cases, the performance is substantially better, indicating that the testing envelope and data quality in the IRT could be far better than is currently available, significantly increasing the benefits to IRT customers.

\section{Upgrades and Enhancements for the Langley National Transonic Facility}

The National Transonic Facility (NTF) is a high-pressure, cryogenic, closed-circuit wind tunnel that uses cold nitrogen gas at high pressure to duplicate true flight aerodynamics. Because of this unique feature, the NTF can accommodate models as small as one-fiftieth the size of an actual aircraft. The NTF has two modes of cooling. In the first mode, liquid nitrogen is sprayed into the circuit. The heat of vaporization to gas and latent heat cools the tunnel structure and dissipates fan heat. In this mode, the NTF provides full-scale-flight Reynolds numbers without an increase in model size. Ambient-temperature air is the test gas in the second mode. Fan heat is removed by chilled water that flows through a cooling coil. The drive system consists of a fan driven by an adjustable speed motor and variable inlet guide vanes for responsive Mach-number control.

The NTF enhancements are focused on improving satisfaction and cost-effectiveness of customer test programs. The project provides modernization of control system hardware, multiple data system advancements, and streamlined data reduction. The most important and extensive of the three work packages is the facility data system upgrades, which improves accuracy, modeling, reduction, and acquisition hardware and software at the tunnel. The control system upgrade work package replaces old technology components currently supported hardware and software configurations as well as allowing high speed communication with the new data systems hardware. Finally, reliability improvements will target the tunnel's weakest areas for action to reduce downtime. The goal of these 
improvements will be to provide a world-class testing center with technical viability that is demonstrated by meeting customer testing, measurement, and condition requirements.

\section{A. Data System Improvements}

Recent studies at NTF have shown that the facility measurement accuracies and repeatability do a marginal job of meeting current commercial high Reynolds number testing demands. Primary contributors limiting performance are balance measurements and calculation issues, model angularity measurements and tunnel conditions that are both measured and calculated. A major common element to these contributors is the existing data acquisition hardware and architecture. The following actions are underway to correct these issues. Note that with each data system computer and software replacement, the existing front-end hardware, wiring, and instrumentation is not affected by this upgrade.

Replacement of the Process Computer System - The Process Computing System (PCS) that performs as the plant state monitor and logging historian, will be upgraded to a current technology based platform capable of continuous recording. The new hardware and software integrates with the other facility data systems such that common components may be shared and configured in a consistent manner between each system. The new system is expandable up to 1028 analog and 64 digital channels and will have the ability to collect and store data at the maximum scan rate for up to 12 hours. Historical data analysis and archiving capability is also included.

\begin{tabular}{|c|c|c|}
\hline $\begin{array}{c}\text { Current PCS DAS } \\
\text { Number of Channels }\end{array}$ & $\begin{array}{c}\text { Current PCS DAS } \\
\text { Throughput @ Scan Rate }\end{array}$ & $\begin{array}{c}\text { Current PCS DAS } \\
\text { Maximum Scan Rate }\end{array}$ \\
\hline $\begin{array}{c}\text { 256 Analog } \\
\text { 16 Digital }\end{array}$ & $5.44 \mathrm{KBps} @ 10 \mathrm{~Hz}$ & $50 \mathrm{~Hz} @ 256$ Channels \\
\hline $\begin{array}{c}\text { New PCS DAS } \\
\text { Number of Channels }\end{array}$ & $\begin{array}{c}\text { New PCS DAS } \\
\text { Throughput @ Scan Rate }\end{array}$ & $\begin{array}{c}\text { New PCS DAS } \\
\text { Maximum Scan Rate }\end{array}$ \\
\hline $\begin{array}{c}\text { 256 Analog } \\
\text { 16 Digital }\end{array}$ & $27.2 \mathrm{KBps} @ 10 \mathrm{~Hz}$ & $200 \mathrm{~Hz} @ 256$ Channels \\
\hline
\end{tabular}

Table 2. Comparison of existing and new PCS data throughput and scan rates.

Replacement of the Research Computer System - The Research Computer System (RCS) that performs the data acquisition and calculations for tunnel parameters, test article measurements and various research specific measurements is also being upgraded to a current technology based platform. The RCS will communicate with the tunnel control system through the upgrades described below to gather tunnel control parameters and measurements. RCS captured data shall have the capability to be time aligned such that differing measurement lag times at various tunnel conditions can be correlated. The new RCS is also expandable up to 1028 analog and 64 digital channels and

\begin{tabular}{|c|l|l|}
\hline $\begin{array}{c}\text { Current RCS DAS } \\
\text { Number of Channels }\end{array}$ & $\begin{array}{l}\text { Current RCS DAS } \\
\text { Throughput @ Scan Rate }\end{array}$ & $\begin{array}{l}\text { Current RCS DAS } \\
\text { Maximum Scan Rate }\end{array}$ \\
\hline $\begin{array}{c}\text { 128 Analog } \\
\text { 16 Digital }\end{array}$ & $5.44 \mathrm{KBps} @ 10 \mathrm{~Hz}$ & $50 \mathrm{~Hz} @ 128$ Channels \\
\hline $\begin{array}{c}\text { New RCS DAS } \\
\text { Number of Channels }\end{array}$ & $\begin{array}{l}\text { New RCS DAS } \\
\text { Throughput @ Scan Rate }\end{array}$ & $\begin{array}{l}\text { New RCS DAS } \\
\text { Maximum Scan Rate }\end{array}$ \\
\hline $\begin{array}{c}\text { 256 Analog } \\
\text { 32 Digital }\end{array}$ & $27.2 \mathrm{KBps} @ 10 \mathrm{~Hz}$ & $200 \mathrm{~Hz} @ 256$ Channels \\
\hline
\end{tabular}

Table 3. Comparison of existing and new RCS data throughput and scan rates.

will have the ability to collect and store data at the maximum scan rate for up to 12 hours.

Replacement of the Dynamic Data System - The dynamic data acquisition system (DDS) is being upgraded as an integral part of the RCS architecture. Data may be collected simultaneously with RCS at rates allowing frequency spectral analysis concurrent with relatively static data from RCS. It can operate independently or in concert with RCS.

Replacement of the Model Prep Area Data System - Upgrade the Model Prep Area (MPA) data acquisition system which performs measurement and calculation of signals generated in the Model Prep Bays to a current technology based platform. The MPA will duplicate all functions and calculations as RCS so that in the event of a failure, components of MPA may stand in for RCS thereby reducing the downtime impact to productivity. 
On-line Data Reduction Software - The Data Reduction Software (DRS) will reside on the RCS and perform all the current data reduction routines. It will be implemented utilizing commercially available analysis and computational software system (e.g. MATLAB $($ )), allowing for rapid development and integration of new methods and options. The DRS will provide real time display capability for all measurements and calculations. All calculations will occur such that each measurement step is concurrent with its calculated values. The DRS will have several advanced balance configuration possibilities, including selectable options to allow balance interaction calculations using either the Langley standard 6 X 27 matrix or the AIAA 6 X 96 matrix. In addition, the balance interactions may be applied after conversion to force or before. The DRS will allow the balance to be connected as a moment device with appropriate interactions applied and resulting forces calculated or as a force balance with appropriate interactions applied. Balance tare routines will be developed to provide tares with upright/inverted measurements that resolve to near zero. The DRS options modifications will also allow balance temperature compensation using non- linear curve fits for up to 9 points on the balance. The curve fit components as well as $\mathrm{X}$, $\mathrm{Y}, \mathrm{Z}$ location on the balance with respect to moment center will be components of the calculation. The balance interaction calculations shall be modified to compensate for up to nine temperature different measurement locations. The RCS running the data reduction software shall 'reduce' a 40,000-point series of test data including file input and output functions within 10 minutes. (The current system requires over five hours performing this task.) The operation of the data reduction software shall not affect the performance of RCS while capturing data.

Other Improvements - The scope of additional improvements is large. Features such as a new Automatic Test Sequencer, data storage on a redundant array of independent disks with tape back-up, video system storage, synchronized time stamping, real time display screens, and more make this effort truly innovative in the advancements in ease of testing and data access/management.

\section{B. Control System Upgrades}

Upgrades to the facility controls at NTF target several weak areas of tunnel infrastructure and instrumentation. To assure performance validation of the new components and site implementation, tunnel testing is included both before and after the upgrades. The tasks are broken down into the following work packages.

Tunnel Control Microprocessors - Three rack-mounted microprocessors function as tunnel pressure controller, tunnel temperature controller, Mach number controller, and model position controller. The microprocessors also include analog safety interlocks, and supervisory functions associated with controlling the tunnel operations. These will be replaced with a single computer for control algorithms and calculations. A programmable logic controller (PLC) will be added to handle the inputs and outputs associated with the interlocks and sequencing previously imbedded in the control microprocessors. Software for the new platforms is currently being written.

PLC Platform Upgrade - Four existing PLCs will be upgraded to a newer, higher speed platform. This includes advanced processors with high speed communication interconnection, new input/output modules and backplanes. Novel manufacturer designs allow plug and play replacement of the hardware, even thought the form factor is completely different. The existing logic is being ported to the compatible application software for the new PLCs. In addition, the fan drive motor health monitoring system and data interfaces will be replaced with new components.

Flow Reference System Study - The existing Mach number measurement system contains equipment and sensors that are no longer manufactured. In order to develop a replacement, highly accurate sensors with wide dynamic ranges are needed. To accurately determine the facility need and the subsequent device specifications, a tunnel uncertainty model has been developed. Using this model in a Monte Carlo simulation with existing test data will provide the information necessary to design a replacement system.

Tunnel Simulation Model - A complete tunnel simulation is being developed using MATLAB® and Simulink®. The NTF has complex control systems with strong interactions and dependencies. For example, Mach number control is effected by tunnel pressure, temperature, fan pressure ratio, and whether the tunnel is operating with air or nitrogen as the test gas. The complexity and wide range of facility operational conditions has limited the optimization of the various control systems due to the high tunnel operational expenses, risks, and extensive commitments of tunnel test time. As a result, minimal tunnel optimization or advanced algorithm development has taken place. Also, the original tunnel control laws were not well documented. The new tunnel model is being rapidly developed with the sophisticated tools currently available and has good correlation with existing tunnel performance data. The goal will be to enable the tunnel operations team, and customers, to simulate various scenarios of tunnel changes and demonstrate performance results without involving the physical hardware.

Validation Tests - A check standard test, T208, was completed in March 2010 using the standard Pathfinder model in both air and cryogenic modes. A follow-up test, T209, is planned next year to compare performance with the new control upgrades, and hopefully the newly installed data system upgrades, although that addition is not a 
criteria for the follow-up test. Comparison of the test data will be a quality assurance and requirements acceptance activity for the contracted elements of the work package.

\section{Reliability Assessment and Improvements}

To improve the operational reliability, three subtasks with in this work packages are being executed to identify downtime sources and how to best approach reduction of the resulting lost time.

Review/Analysis of Lost Time - A detailed review and analysis of operational lost time history at the NTF is being conducted. The purpose is to identify the operational lost time and the associated cost impact per lost time per system over the last four fiscal years $(2006,2007,2008$, \& 2009). Included in the analysis is data from all related Mishap Investigations.

A 'Lost Time Analysis Report' that details the ranking (from greatest to least) of the operational lost time per system and associated cost influence per system will be prepared from the analysis. This report will contain a brief description of the lost time event and clearly identify repeat events or safety related events. Any reliability issues that are considered safety critical will be prioritized.

On-Site Condition Assessment - An on-site system condition assessment is also being conducted to evaluate the current condition of major facility systems and subsystems. The assessment will address the physical condition of each major system and associated subsystems; evaluate the effectiveness of the current maintenance program, spare parts inventory and systems operations. Facility systems will be compared to 'industry standards' of maintenance and reliability of similar equipment. The condition assessment will be summarized in a report, including an evaluation of the systems with regard to safety of equipment, safety of workforce, system reliability, an estimation of remaining useful life and likelihood and cost of a system or component failure.

Recommendations and Review - The results of the Review and Analysis of Lost Time and the On-Site Condition Assessment will be compiled in a Final Recommendations Report. The information provided will be used to improve the NTF's reliability through reduced operational downtime. The Final Recommendations Report will include findings and detailed recommendations that are necessary to improve the NTF's reliability in priority order necessary to improve reliability and reduce lost time and costs. Implementation of the items will begin after the report has been accepted, and will continue as schedule and funding is available.

\section{Modifications at the Langley 14x22 Low Speed Wind Tunnel}

In the past, this facility has been used to assess conventional performance for low-speed tests of powered and unpowered models of various fixed- and rotary-wing civil and military aircraft over a wide range of takeoff, landing, cruise, and high angle-of-attack conditions. Nevertheless, the tunnel can be reconfigured for acoustic, tethered freeflight and forced-oscillation testing. The project focuses on infrastructure modifications that will provide the facility capability to accomplish a groundbreaking test program and establish a benchmarking standard with leading edge technology for acoustic measurements.

The 14x22 modifications will support the Environmentally Responsible Aviation (ERA) Project under ARMD's newly formed Integrated Systems Research Program (ISRP). Through the partnership with ISRP using ARRA funding, ATP is providing two significant efforts. First, a traverse mechanism design to hold a specialized microphone phased array and second, fuel storage and delivery equipment for a novel Compact Jet Engine Simulator (CJES). Developing technologies that will enable dramatic reductions in aircraft noise is a critical element of NASA's ERA program. The future role for the $14 \times 22$ as a premier acoustic research facility starts with the Hybrid Wing Body (HWB) Acoustic Test Program.

\section{A. Fuel and Purge Systems Infrastructure}

Testing the proposed phenomena in a wind tunnel requires the use of engines scaled to the size of the model. The CJES developed for acoustic and propulsion integration studies in the 14x22 are hot dual stream subsonic engines at a $5.8 \%$ scale of a 75,000 pound thrust engine. The CJES will generate scaled thrust and combustion products appropriate to the proposed engines and mimic aero acoustic noise generated by aircraft engines. In order to accomplish this, propane and air are supplied to the CJES where they are mixed and burned. Various discrete engine locations coupled with a movable model sting allow for characterizing total acoustic interactions with the model.

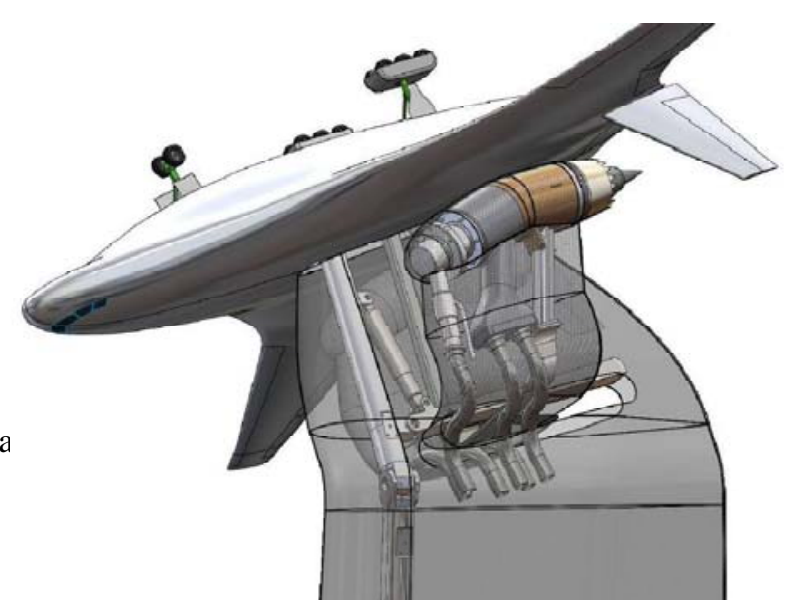


In order to support a typical test day (6 hours of testing) of continuous operation with the scale model CJESs, a propane storage and delivery system is being designed and built to bring the fuel to an interface point on the CJES model fuel pallet. The fuel system is designed to provide 0.3 pounds-mass per second to the CJES from a 250 gallon run tank. The run tank can be filled and emptied via a connection to a 2500 gallon liquid propane storage tank.

A parallel nitrogen pressurization and purge system is also being provided to safely remove air initially from the fuel lines and to inert the lines after a test run. The nitrogen will also be used to pressurize the fuel run tank during operations. The systems are designed to interface with the CJES control pallet as the tunnel model support cart is moved in and out of the test section.

\section{B. Microphone Traverse Mechanism Design}

While the high-bypass ratio simulator engines are running, it is envisioned that acoustic noise patterns can be mapped with a movable multimicrophone recording system. To accurately develop acoustic maps of engine noise, sensitive microphone arrays must be positioned out-of-flow on a stable mechanism that provides accurate twodimensional positioning.

The biggest challenge to gathering high fidelity acoustic measurements at the $14 \times 22$ is overcoming the flow induced vibrations of the tunnel structure into a traverse framework holding the microphone array. Additionally, there is a small envelope of space overhead between the needed ceiling acoustic insulation and the lower boundary of the 'out-of-flow' region where the array panel can be positioned. Preliminary tunnel measurements and existing acoustic mapping techniques have established the required

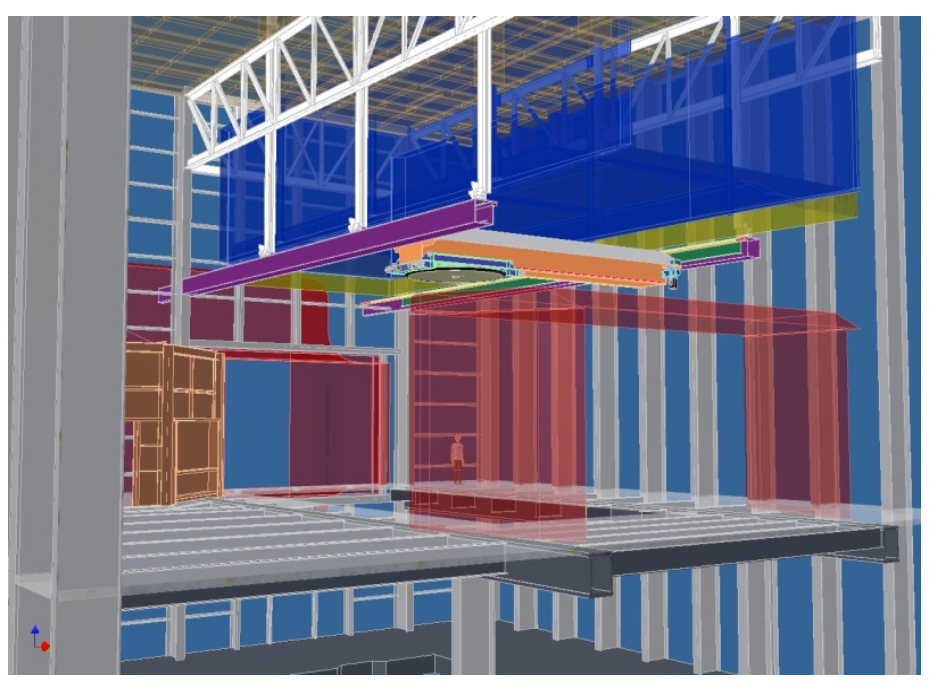

Figure 7. Model of traverse concept in the $14 \times 22$ test section. positioning accuracies and vibration limits. A rigorous, high performance trade study is being conducted, including three-dimensional modeling of proposed frames and attachment methods. These techniques check for physical interferences throughout the range of traverse motion and simulate the structural dynamic performance. A downselect process will provide the best solution overall and define the constraints for the final design work.

In order to provide the necessary access envelope at the flow inlet end of the test section, a portion of the existing control room and a helicopter blade protective blast wall have to be removed. A control room modification is required to reduce the footprint while maintaining the existing controls equipment.

\section{Rotorcraft Test Cell Upgrades}

The 14x22 also has a long history of performing rotorcraft research, and over the years has developed an infrastructure base that supports this research. The Rotor Test Cell, an area of the facility dedicated to rotor performance investigations is in need of significant improvements. These improvements, while not costly, bring expanded control room areas and better equipment and instrumentation to support upcoming tests. ATP is providing the project execution of these additional 14x22 modifications to advance NASA's Subsonic Rotary Wing research.

Expansion of Rotor Test Cell Control Room - Rotorcraft research in the Rotor Test Cell now routinely involves multiple test objectives and thus more researchers, especially those with specialized test techniques and instrumentation. To effectively and efficiently conduct research in the Rotor Test Cell, when the test involves multiple objectives, the entire test team needs to be located in the same control room. A new two-story control room is being constructed to house all the rotor operational staff and additional researchers using specialized instruments.

Model Interface Racks (MIF) Environmental Cabinets - The MIF racks provide the instrumentation interface between research models and the 14x22 tunnel data system. The current MIF racks are over 25 years old and contain worn components that create data measurement quality and reliability problems. Four environmentally-controlled equipment racks will replace the existing units.

High Speed Cameras - The quality of the measurement of pressure sensitive paint (PSP) is directly related to the amount of light used to illuminate the paint and the sensitivity of the cameras used to record the PSP images. Two 
CMOS cameras with 1280x1024-pixel resolution and image capture rate up to 520 frames per second are being installed to improve the quality of the PSP rotor data.

Model Instrumentation and Patch Panel/Cabling - Connections and cabling of instrumentation that measures rotor system parameters is critical to both the operation of the rotor system and the quality of the data produced during a test program. A reliable, new patch panel and signal cabling maintains measured data quality and reduces the time required to connect instrumentation. The next scheduled test in the rotor test cell will be a rotor downwash/outwash investigation. High accuracy dynamic pressure transducers will be provided to make measurements as needed on the fuselage and ground plane to characterize the flow of the rotor downwash and its effect on ground-plane objects.

\section{Additional Benefits and Challenges of the Recovery Act Projects}

While the primary technical gain for NASA from the implementation of these major projects is given above in the descriptions, there are additional intangible benefits and some difficult challenges. The overall use of wind tunnels for research testing has declined over the past years and along with that, the ability to attract, retain, and develop wind tunnel application engineering. A major challenge of executing these projects is to bring them on line successfully in concert with ongoing facility operations.

\section{A. Additional Benefits}

NASA and its Contractor workforce will gain from these large, fast track projects through the experience and maturity of the people involved. NASA is losing the corporate wind tunnel operations knowledge base through attrition. In addition, NASA has not attracted new talent because of increasingly attractive competition of hightechnology jobs. Through these projects, both labor segments are gaining hands-on involvement, building the much needed resource competency and re-establishing a mature work force that can execute difficult wind tunnel projects with the critical knowledge skills that only come from actual involvement in such efforts. Subsequent to the completion of the projects, additional research jobs, and employment opportunities will exist utilizing these advancements.

\section{B. Challenges}

The facilities to be upgraded are all heavily utilized and represent unique test capabilities. The challenge of integrating installation and checkout of new systems or modifications with customer test schedules usually results in compromise and delays. Managing customer milestone deliveries and smoothly executing the transition from operation to construction represent additional workloads on the facility managers and staff. The impacts to the projects can be nontrivial as well. Costs resulting from extended schedules or Government imposed workarounds can require significant contingencies. However, because of the strict and accelerated spending requirements of the ARRA, holding contingencies well into project maturity is not allowed. The Center-located ATP project managers, along with the affected facility managers, have to develop strategies unique to each individual tunnel and testing schedule to meet these conflicting requirements successfully. In any case, ATP must be prepared to cover contingency shortfalls in the next fiscal year, which will certainly affect the facility budgets.

\section{Conclusion}

The new capabilities of icing research and acoustic noise mapping will be instrumental in future aircraft safety developments and environmentally responsible aircraft designs. The benefit to NASA, its customers, and ultimately the public is possible because of the major funds provided by the ARRA.

In order to continue providing new capabilities that research entities are envisioning and maintain safe and reliable facilities that can be made available when needed, projects like the ARRA ones are much needed. The projected out-year budgets for ATP to manage and maintain this core set of facility capabilities are flat, at best. Specialized funding sources are rare and unpredictable, and by necessity, ATP and Centers must always be prepared to take advantage of opportunities like the ARRA and immediately start major improvements.

\section{Acknowledgments}

The author would like to thank each of the project teams across the three NASA Centers for the outstanding work in executing these projects. In addition, special thanks to the individual Project Managers for assistance provided in pulling together the information presented herein - Mr. Ed Newman, Ames Research Center; Mr. Jeff Chambers, Glenn Research Center; and Mr. Steve Syrett, Langley Research Center. Finally, thanks and recognition are due to Jacobs Technology Group, for their extensive project work and help in providing material for this paper. 